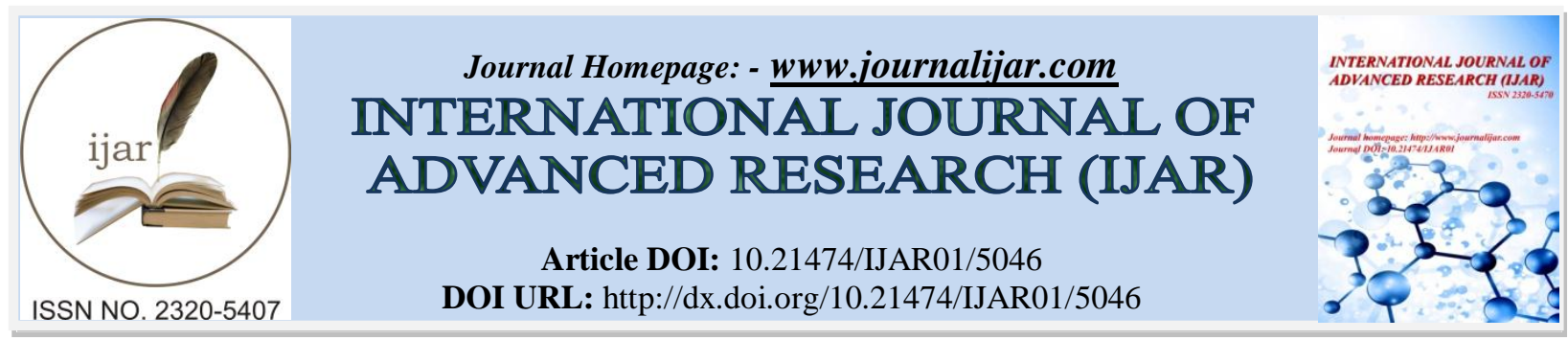

RESEARCH ARTICLE

\title{
PREVALENCE OF INFECTIOUS VAGINITIS: ANALYSIS OF DATA FROM VAGINAL SWABS EXAMINED IN THE CENTRAL LABORATORY OF KORLE BU TEACHING HOSPITAL, GHANA.
}

\author{
${ }^{*}$ Ali Samba ${ }^{1}$, Kareem Mumuni ${ }^{1}$ Opuni $\mathrm{A}^{2}$, Dankwah $\mathrm{T}^{2}$, Sowah $\mathrm{A}^{2}$ and Mashud $\mathrm{M}^{\mathbf{2}}$. \\ 1. Department of OBGYN, Univ. of Ghana School of Medicine and Dentistry. Box 4236, Korle-Bu. Accra. \\ Ghana. \\ 2. Department of Microbiology, Korle-Bu Teaching Hospital. Box 77. Korle-Bu. Accra. Ghana.
}

\section{Manuscript Info}

Manuscript History

Received: 02 June 2017

Final Accepted: 04 July 2017

Published: August 2017

Key words:-

vaginitis, bacterial, candida, vaginosis,

vaginal swab.

\section{Abstract}

Aim: Vaginitis usually results from an infection and can be caused by several different microorganisms, with yeast species generally the predominant pathogens. However, since the aetiological profile of infectious vaginitis can be diverse and has been shown to significantly vary from country to country, the aim of this study was to determine this profile amongst Ghanaian women.

Methods: This was a retrospective record review of 1,453 High Vaginal Swabs (HVS) collected between January and December 2014 at the Central Laboratory of the Korle Bu Teaching Hospital and obtained from women with vaginal discharge who presented at the gynaecological unit for care. All HVSs were cultured on blood and chocolate agars for $18-24 \mathrm{~h}$ at $37^{\circ} \mathrm{C}$. Colonial morphology, Gram reactions and specified biochemical tests were performed for the identification of isolates. Analysis was done using simple proportions/ frequency for isolated organisms and age distribution of patients.

Results: Pathogenic organisms were isolated in 567 out of 1453 HVSs (39\%). Among these, Candida species, not otherwise specified, were the most prevalent microorganisms causing infectious vaginitis $(84.5 \%$, $\mathrm{n}=479)$. Bacterial isolates accounted for $15.5 \% \quad(\mathrm{n}=88)$ with Escherichia coli being the most commonly involved specie. As high as $47.4 \%$ of isolates were commensals or normal vaginal flora and $13.6 \%$ had no growth of microorganisms.

Conclusions: This study demonstrates the etiological predominance of Candida infection, but also underlines the noticeable prevalence of bacterial vaginitis. Given this etiological heterogeneity of infectious vaginitis, a broad-spectrum combination treatment may be appropriate as first-line empirical therapy for infectious vaginitis especially in low resource centres were cultures are not readily available.

Copy Right, IJAR, 2017,. All rights reserved.

\section{Introduction:-}

Vaginal discharge is one of the commonest gynaecological complaints and one of the most frequent reasons that prompt women to seek a gynaecological consultation [Henn, 2005; Sivaranjini, 2013]. 
Some degree of vaginal discharge is normal and healthy for women in their childbearing years [FSRH, 2012]. It derives from the physiological secretion of cervical and Bartholin's glands and desquamation of vaginal epithelial cells resulting from bacterial action in the vagina [da Fonseca, 2013]. The quantity and type of physiological vaginal discharge vary during the menstrual cycle as a result of hormonal fluctuations [FSRH, 2012]. However, vaginal discharge is considered abnormal or pathological when it is more abundant, has an unpleasant odor and/or, abnormal colour, consistency and is accompanied by vulval or vaginal itching, dysuria, and/or dyspareunia [da Fonseca, 2013].

In women aged 15 to 49, abnormal vaginal discharge is the second leading cause of lost years of healthy life [da Fonseca, 2013] and imposes a significant negative impact on their health-related quality of life, especially on the physical domain [Sami, 2014; Valsangkar, 2014]. This gynecological morbidity was also shown to be a strong predictor for future HIV acquisition [Abbai, 2016]. Furthermore, during pregnancy, pathological vaginal discharge can cause serious harm to the mother and their children including prematurity, low birth weight, chorioamnionitis, post-partum endometritis, and post-cesarean wound infection [da Fonseca, 2013].

Vaginal infection, also known as vaginitis, including bacterial vaginosis, aerobic vaginitis, Candida albicans and trichomoniasis accounts for the majority of the cases of vaginal discharge [Donders, 2002; Mylonas and Bergauer, 2011; FSRH, 2012; Fan, 2013; Frobenius and Bogdan, 2015; Rice, 2016] and results from an increased colonization by different pathogenic microorganisms. Numerous studies/reviews attempted to determine the frequency of the different types of vaginitis and provided percentages that varied considerably between countries and world regions, and across various groups within countries. The frequency for bacterial vaginosis ranged between 17 to $19 \%$ in family-planning or student health clinics, 24 to $37 \%$ in sexually-transmitted disease clinics, and 10 to $29 \%$ among pregnant women [Sobel, 1997; Kenyon, 2014]. Vulvovaginal candidiasis is diagnosed in up to 40\% of women with vaginal complaints [Ilkit and Guzel, 2011]. The prevalence of diagnosed aerobic vaginitis was estimated between 5 and 10.5\% [Tansarli, 2013] while the annual incidence of trichomoniasis (per 1000 persons) in the 15-49 year-oldwomen ranged between 11.7 in East Asia and Pacific regions to 119.4 in Sub-Saharan Africa [Kenyon, 2014].

The identification of the type of vaginitis and of the causative organism(s) involved in these infections is therefore recommended before initiating any treatment. It generally consists of assessing the clinical and sexual history of the woman, and performing a vulvo-vaginal examination with measurement of the vaginal $\mathrm{pH}$, and simple laboratory investigations, including microscopy and microbiological culture of the vaginal discharge [FSRH, 2012]. This classic approach has been promoted by professional organizations [FSRH, 2012] and an abundant clinical literature that emphasizes the importance of making a precise diagnosis before treating the patient [Anderson and Karasz, 2005].

However, in routine clinical practice, vaginal discharge is not investigated microbiologically in all settings, especially in poor-resource ones, because it is costly and due to the limited availability of well-equipped facilities for fully diagnosing these infections [Rekha and Jyothi, 2010; Kapoor, 2016]. Most of the time, a presumptive diagnosis is made based on the nature of the discharge, without any laboratory investigations and treatment is initiated based on clinical findings alone [Rekha and Jyothi, 2010]. This approach is consistent with the FSRH guidance which indicates that women experiencing vaginal discharge who are at low risk of sexually-transmitted infection can be treated by syndromic or empirical management [FSRH, 2012].

Consistently, in Ghana, a careful risk assessment of women with vaginal discharge is generally used to exclude other potential diagnosis (e.g. sexually-transmitted infections), and to identify the most likely etiology of the discharge as well as the appropriate treatment regimens. Microbiological culture is usually reserved to cases of recurrent vaginal discharge and/or treatment failure [Ghanaian Ministry of Health, Standard Treatment Guidelines, $2010]$.

In this context, it may be helpful for those physicians who have no laboratory facility to recognize the different presentations of vaginal discharge but also to know the epidemiological data in their geographical area so that their diagnosis can be as accurate as possible and the symptoms treated according to its corresponding etiology. Although numerous studies have been carried out in developed countries to document both the "normal" vaginal flora and the flora associated with vaginal discharge, there is insufficient knowledge of the etiology of infective vaginal discharge in many developing countries. The aim of the present study was to determine the microbiological profile of 
(symptomatic) vaginal discharge in the urban area of Accra (Ghana) in order to ensure a rationale choice for both empirical and definitive antimicrobial treatment of vaginal discharge.

\section{Materials and Methods:-}

\section{Study design:-}

This retrospective study was conducted at the Microbiology Department of the Central Laboratory of the Korle Bu Teaching Hospital, which is a referral hospital located in the capital of Ghana, Accra. The approval and permission for the study was granted by the departments of Microbiology and Reproductive Health of the Korle-Bu Teaching hospital. High vaginal swabs routinely delivered at this department for microbiological examination from January to December 2014 were further used for this research work. The data was extracted from record books (specimen log books ) on HVS from $1^{\text {st }}$ January $-31^{\text {st }}$ December 2014. Variables collected included age of patients and culture results with types of isolates. The records did not have other sociodemographic information such as educational level, occupation etc.

Analysis of data was by simple proportions/ frequencies of culture results and age distribution of patients and presented in text, tables and figures.

\section{Results:-}

A total of 1453 high vaginal swabs collected from patients with vaginal discharge and suspicion of vaginitis were received by and worked on by the Microbiology Department of the Central Laboratory of the Korle Bu Teaching Hospital over the period extending from January to December 2014.

No data on the requesting department or ward was available for $61.4 \%(n=892)$ of the HSVs. Out of the HSVs with information on the requesting department $(n=561,38.6 \%)$, most were outpatient cases from the Korle Bu Teaching Hospital, only three requests came from other medical facilities. Samples were obtained from women of different age groups (mean age: 31 , range: $1-90$ ). However, more than $87 \%$ of samples was collected from patients within the childbearing age range (15-45 years).

Of the 1453 high vaginal swabs cultured, 86.4\% $(n=1256)$ resulted in positive cultures.( table 1).

A majority of the positive cultures had normal commensal flora, i.e. the majority of bacterial forms were Lactobacilli $(54.78 \%, \mathrm{n}=688)$. Candida species were isolated from 38.14\% (n=479) of HVSs. In 48 high vaginal swabs, culture retrieved the following bacteria: Escherichia coli $1.35 \%(\mathrm{n}=17)$, Streptococcus pyogenes $0.64 \%($ $\mathrm{n}=8)$, Pseudomonas aeruginosa $0.48 \%(\mathrm{n}=6)$, Streptococcus beta haemolyticus $0.32 \%(\mathrm{n}=4)$, Citrobacter koseri $0.32 \%(\mathrm{n}=4)$, Enterobacter spp. $0.32 \%(\mathrm{n}=4)$, Klebsiella spp. $0.32 \%(\mathrm{n}=4)$ and Neisseria gonorrhea $0.08 \%(\mathrm{n}=1)$ as shown in table 2 .

Table 1:- Microbiological culture results of all HVS $\mathrm{N}=1453$

\begin{tabular}{|l|l|l|}
\hline Culture Result & Frequency(n) & percent \\
\hline positive & 1256 & 84.4 \\
\hline negative & 197 & 13.6 \\
\hline
\end{tabular}

Table 2:- Types of isolates of positive cultures $\mathrm{N}=1256$

\begin{tabular}{|l|l|l|}
\hline Isolate & Frequency(n) & percent \\
\hline Lactobacilli & 688 & 54.78 \\
\hline Candida species & 479 & 38.14 \\
\hline Escherichia coli & 17 & 1.35 \\
\hline Streptococcus pyogenes & 8 & 0.64 \\
\hline Pseudomonas aeruginosa & 6 & 0.48 \\
\hline Streptococcus beta haemolyticus & 4 & 0.32 \\
\hline Citrobacter koseri & 4 & 0.32 \\
\hline Enterobacter spp. & 4 & 0.32 \\
\hline Klebsiella spp. & 4 & 0.32 \\
\hline Neisseria gonorrhea & 1 & 0.08 \\
\hline
\end{tabular}


A bacterial colonization (not otherwise characterized with the experimental conditions chosen) was reported in another 41 high vaginal swabs.

The distribution of the identified microorganisms among the different age group is shown in Figure 1. The highest frequency of Candida or bacteria positive samples was obtained in the 20-29 year age group followed by the 30-39 and 40-49 year age groups.

Fig 1:- Distribution of results within the different age group

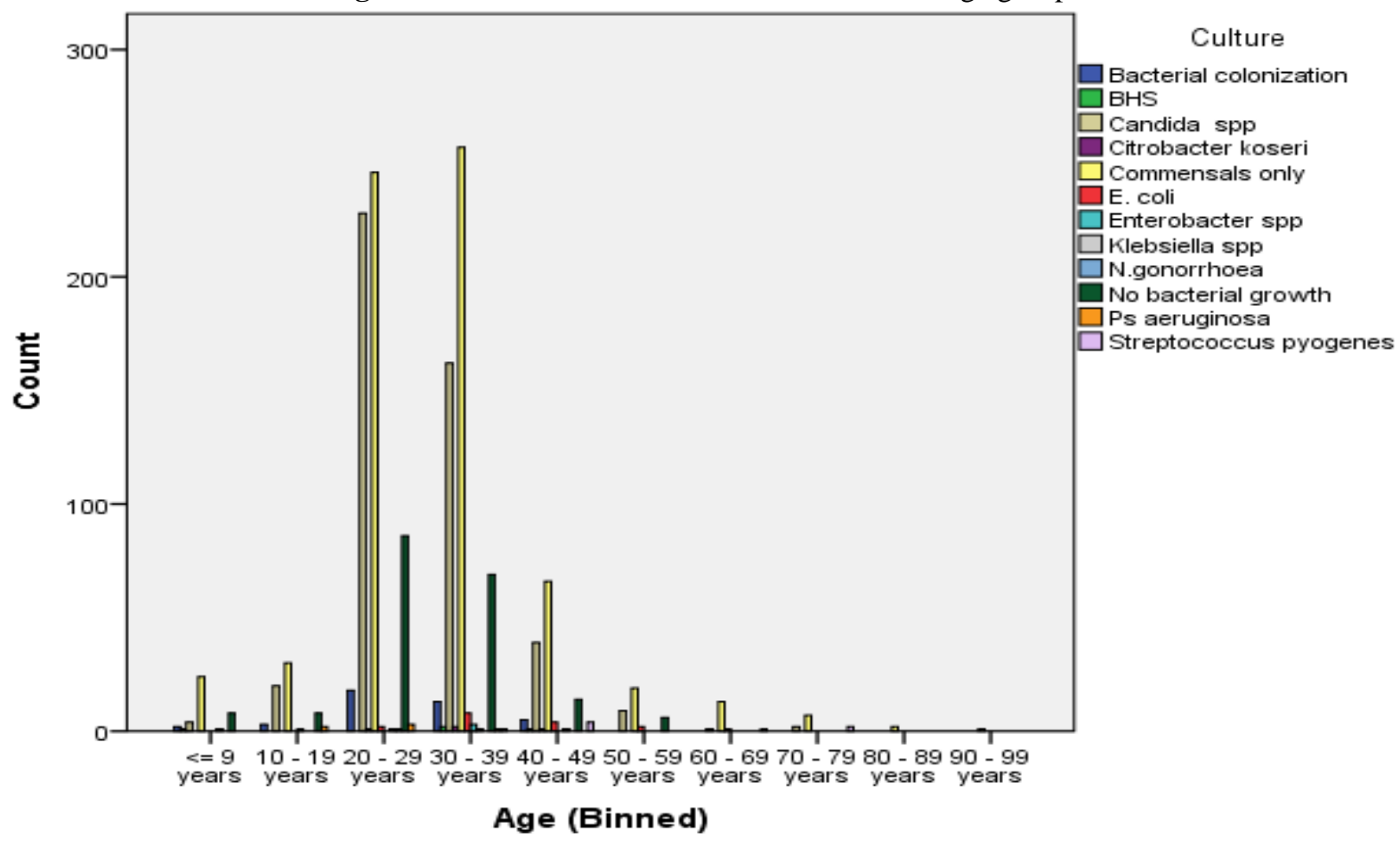

\section{Discussion:-}

This study found $86.45 \%$ prevalence of positive cultures, most of which were commensals, this though not unexpected, it is difficult to determine whether they could be associated with the abnormal vaginal discharge since an overgrowth of commensals would cause abnormal discharge. Other studies such as that of Masand D et al (2015) found similar or slightly higher ( $99 \%$ ) rates of positive cultures.

There was a $13.6 \%$ of no growth or negative cultures which is slightly higher than the $11 \%$ found by Masand D et al (2015). No growth can be attributed to several factors including non-infectious causes, use of inappropriate culture media for fastidious and anaerobic organisms. It may also be due to inappropriate collection and transport of specimen leading for instance to drying of swabs.

In this study Candida species were isolated from 33.0\% ( $\mathrm{n}=479)$ of HVSs. These results are consistent with the findings of other studies conducted in India, Turkey, Noth West Africa: 32.7\% prevalence for (Agyarko-Poku, 2011), 34.2\% (Apea-Kubi, 2005) and 21\% (Abruquah, 2012).

The prevalence of bacteria associated vaginal discharge was found to be $15.7 \%$, which is higher than the $4.5 \%$ found by Di Bartolomeo et al(2000), but lower than the $23 \%$ found by Klufio et al (1995) and even much lower than the 53\% recorded by Masand et al (2015).This wide variation could be due in part to the differences in specimen collection and culture media available and techniques used as well as age distribution of the study populations. For instance the highest frequency of Candida or bacteria positive samples was obtained in the 20-29 year age group. Similar peak age incidence in case of infectious vaginitis was noted in other studies done by Rekha et al (2010), and in Masand, Patel and Gupta (2015). And so it could be inferred that the higher this age group as part of the study population the more likely the prevalence of bacteria isolation will be high. 
The most common bacteria isolated was E.coli at $19 \%$ which is lower than the $25.8 \%$ was recorded by Deepthy et al (2016) , but lower than the $13.7 \%$ by Shamim et al (2008). The least isolated was N. gonorrhoeae at $1.1 \%$ which is consistent with the $1 \%$ by Wulu et al (2015). This is good news and indeed should be even much lower, since it is a sexually transmitted organism. However Wiesenfeld recorded a prevalence of $20 \%$, reasons for this wide variation is not apparent and will remain speculative with the inherent limitations of retrospective studies. The limitations of this study include the non-availability of certain special culture media thus limiting isolation of certain organisms.

\section{Conclusion:-}

This study demonstrates the etiological predominance of Candida infection in infectious vaginitis, but also underlines the noticeable prevalence of bacterial vaginitis. Given this etiological heterogeneity of infectious vaginitis, a broad-spectrum combination treatments may be appropriate as first-line empirical therapy for infectious vaginitis.

\section{Literature References:-}

1. Abbai NS, Wand H, Ramjee G. Biological factors that place women at risk for HIV: evidence from a large scale clinical trial in Durban.

2. Apea-Kubi KA, Bright Sakyi, Shinya Yamaguchi, David Ofori-Adjei. Bacterial vaginosis, Candida albicans and Trichomonas vaginalis infection in antenatal and gynaecological patients in Ghana. Tropical Journal of Obstetrics and Gynaecology Vol. 22(2) 2005: 108-112

3. da Fonseca TM, Cesar JA, Mendoza-Sassi RA, Schmidt EB. Pathological Vaginal Discharge among Pregnant Women: Pattern of Occurrence and Association in a Population-Based Survey. Obstet Gynecol Int. 2013; 2013: 590416. doi: 10.1155/2013/590416.

4. Deepthy U.V, Deepthy B J, Golgi Suresh Lt. Col Valson H. Prospective Study on the Microbiological Profile of Vaginosis Among Women of Reproductive Age Group. India Journal Of Applied Research Volume : 6 | Issue : 9 | September $2016 \mid$ ISSN - 2249-555X | IF : $3.919 \mid$ IC Value : 74.50

5. Di Bartolomeo S, Rodriguez M, Sauka D, Alberto De Torres R. Microbiologic profile in symptomatic pregnant women's genital secretions in Gran Buenos Aires, Argentina. J Infect. 2000 Sep; 41 (2):162-6. PMID:1133358.

6. Donders, G.G.G., Vereecken, A., Bosmans, E., Dekeersmaecker, A., Salembier, G., Spitz, B. Definition of a type of abnormal vaginal flora that is distinct from bacterial vaginosis: aerobic vaginitis. Br. J. Obstet. Gynaecol. 2002; 109: 34-43.

7. Faculty of sexual and reproductive healthcare (FSRH). Clinical Guidance. Management of vaginal discharge in non-genitourinary medicine settings. Clinical effectiveness unit. February 2012. ISSN 1755-103X.

8. da Fonseca TM, Cesar JA, Mendoza-Sassi RA, Schmidt EB. Pathological Vaginal Discharge among Pregnant Women: Pattern of Occurrence and Association in a Population-Based Survey. Obstet Gynecol Int. 2013; 2013: 590416. doi: 10.1155/2013/590416.

9. Fan A, Yue Y, Geng N, Zhang H, Wang Y, Xue F. Aerobic vaginitis and mixed infections: comparison of clinical and laboratory findings. Arch Gynecol Obstet. 2013; 287: 329-35.

10. Frobenius W, Bogdan C. Diagnostic Value of Vaginal Discharge, Wet Mount and Vaginal pH - An Update on the Basics of Gynecologic Infectiology. Geburtshilfe Frauenheilkd. 2015; 75(4): 355-366.

11. Gupta Sapna Goyal Ankur Singh Saroj Agrawal BM. Outcome of routine microbiological screening for lower genital tract infections in symptomatic non-pregnant females complaining infertility. IOSR Journal of Dental and Medical Sciences (IOSRJDMS) eISSN: 2279-0853, pISSN: 2279 - 0861.Volume 13 Issue 1 VerIII (Jan. 2014), PP 26-29

12. Ilkit M, Guzel AB. The epidemiology, pathogenesis, and diagnosis of vulvovaginal candidosis: a mycological perspective. Crit Rev Microbiol. 2011;37(3): 250-61. doi: 10.3109/1040841X.2011.576332.

13. Henn EW, Kruger TF, Siebert TI. Vaginal discharge reviewed: the adult pre-menopausal female. SA Fam Pract. 2005; 47(2): 30-38.

14. Kapoor B, Kapoor A, Shah S,Vora N. Study of prevalence of various disorders and presenting complaints in patients of vaginal discharge. J Evolution Med Dent Sci 2016; 5(1): 87-91, doi: 10.14260/jemds/2016/20

15. Karthika J, Keerthana D, Siv A, Divya G, Jayalakshmi S. The aerobic bacterial profile of High Vaginal Swab in Sub Urban Chennai. IJBPAS, April, 2015, 4(4): 2042-246.

16. Kenyon C, Buyze J, Colebunders R. Classification of incidence and prevalence of certain sexually transmitted infections by world regions. Int J Infect Dis. 2014; 18: 73-80. doi: 10.1016/j.ijid.2013.09.014. 
17. Klufio CA, Amoa AB, Delamare O, Hombhanji M, Kariwiga G, Igo J. Prevalence of vaginal infections with bacterial vaginosis, Trichomonas vaginalis and Candida albicans among pregnant women at the Port Moresby General Hospital Antenatal Clinic. P N G Med J. 1995 Sep; 38(3):163.

18. Mahdieh G, Hoda F, Naser K, Mohsen S-H, Reza T O. Assessing the prevalence of bacterial vaginosis among infertile women of Qom city. Iran J Microbiol. 2014 Dec; 6(6):404-408.

19. Masand DL, patel J, Gupta S. Utility of microbiological profile of symptomatic vaginal discharge in rural women of reproductive age group. J Clin Diagn Res. 2015 Mar; 9(3):QC04-7.

Doi 10.7860/JCDR/2015/1216.5623. Epub 2015 Mar 1

20. Ministry of Health. Republic of Ghana. Standard Treatment Guidelines. Chapter 17: Sexually Transmitted Infections. Sixth edition, 2010.

21. Mulu W, Yimer M, Zenebe Y, Abera B. Common causes of vaginal infections and antibiotic susceptibility of aerobic bacterial isolates in women of reproductive age attending at Felegehiwot Referral Hospital, Ethiopia: a cross sectional study. BMC Womens Health. 2015 May 13;15:42. doi: 10.1186/s12905-015-0197-y.

22. Mylonas I, Bergauer F. Diagnosis of vaginal discharge by wet mount microscopy: a simple and underrated method. Obstet Gynecol Sury. 2011; 66(6): 359-68. doi: 10.1097/OGX.0b013e31822bdf31

23. Puri KJ, Madan A, Bajaj K. Incidence of various causes of vaginal discharge among sexually active females in age group 20-40 years. Indian J Dermatol Venereol Leprol. 2003 Mar-Apr; 69(2): 122-5.

24. Rekha S, Jyothi S. Comparison of visual, clinical and microbiological diagnosis of symptomatic vaginal discharge in the reproductive age group. Int J Pharm Biomed Res. 2010; 1(4): 144-148.

25. Rice A, El Werdany M, Hadoura E, Mahmood T. Vaginal discharge. Obstetrics, Gynaecology and Reproductive Medicine. 2016; 26(11): 317-323.

26. Sami N, Ali TS, Osama M. Quality of life among women with symptoms of gynecological morbidities: results of a cross-sectional study in Karachi, Pakistan. J Obstet Gynaecol Res. 2015 Apr; 41(4): 608-14. doi: 10.1111/jog.12614.

27. Sangeetha KT, Saroj Golia, Vasudha C.L. A study of aerobic bacterial pathogens associated with vaginitis in reproductive age group women (15-45 years) and their sensitivity pattern. Int J Res Med Sci. 2015 Sep; 3(9):2268-2273

28. Shamim Mumtaz, Mumtaz Ahmad*, Irum Aftab, Naeem Akhtar, Masood ul Hassan,

29. Abdul Hamid. Aerobic vaginal pathogens and their sensitivity pattern. J Ayub Med Coll Abbottabad 2008;20(1)

30. Sivaranjini R, Jaisankar T, Thappa DM, K umari T, Chandrasekhar L, Malathi M, Parija S, Habeebulah S. Spectrum of vagial discharge in a tertiary care setting. Trop Parasito. 2013 Jul; 3(2): 135-9. Doi:10.4103/2229. 5070.122140 .

31. Sobel JD. Vaginitis. N Engl J Med. 1997; 337(26): 1896-903.

32. Tansarli GS, Kostaras EK, Athanasiou S, Falagas ME. Prevalence and treatment of aerobic vaginitis among non-pregnant women: evaluation of the evidence for an underestimated clinical entity. Eur J Clin Microbiol Infect Dis. 2013; 32(8): 977-84. doi: 10.1007/s10096-013-1846-4.

33. Valsangkar S, Selvaraju D, Rameswarapu R, Kamutapu S. Impairment of quality of life in symptomatic reproductive tract infection and sexually transmitted infection. J Reprod Infertil. 2014; 15(2): 87-93. 